\title{
Calcium is a Competitive Inhibitor of Gentamicin-Renal Membrane Binding Interactions and Dietary Calcium Supplementation Protects Against Gentamicin Nephrotoxicity
}

\author{
H. David Humes, Malinee Sastrasinh, \\ and Joel M. Weinberg \\ Departments of Internal Medicine, Veterans Administration \\ Medical Center and University of Michigan, \\ Ann Arbor, Michigan 48105
}

bstract. The divalent cations, $\mathrm{Ca}^{++}$and $\mathrm{Mg}^{++}$, are known to competitively inhibit a large number of aminoglycoside-membrane interactions, so that $\mathrm{Ca}^{++}$ prevents both the neurotoxic and ototoxic effects of these antibiotics acutely in vitro. Since gentamicin-induced plasma and subcellular membrane damage appear to be critical pathogenetic events in gentamicin nephrotoxicity, $\mathrm{Ca}^{++}$may play a similar protective role in gentamicininduced acute renal failure. To test this possibility in vivo, rats (group 2) were given a $4 \%$ calcium (in the form of $\mathrm{CaCO}_{3}$ ) supplemented diet to increase delivery of $\mathrm{Ca}^{++}$ to the kidney and administered single daily subcutaneous injections of gentamicin, $100 \mathrm{mg} / \mathrm{kg}$, for $10 \mathrm{~d}$. Compared with a simultaneously studied group (group 1) of rats receiving identical gentamicin dosages and normal diets, $\mathrm{Ca}^{++}$supplementation ameliorated gentamicin-induced acute renal failure. After 10 doses of gentamicin, bloodurea nitrogen values in group 1 averaged $213 \pm 15$ (SE) and $25 \pm 3(P<0.001)$ in group 2 . The progressive decline in renal excretory function, as measured by BUN, in group 1 animals was accompanied by simultaneous declines in renal cortical mitochondrial function and elevations in renal cortex and mitochondrial $\mathrm{Ca}^{++}$content, quantitative indices of the degree of renal tubular cell injury. Oral $\mathrm{Ca}^{++}$loading markedly attenuated these gentamicin-induced derangements. After eight and 10 doses

Dr. Humes is an Established Investigator of the American Heart Association. Dr. Weinberg is a Research Associate of the Veterans Administration.

Received for publication 7 December 1982 and in revised form 31 August 1983.

J. Clin. Invest.

(c) The American Society for Clinical Investigation, Inc.

$0021-9738 / 84 / 01 / 0134 / 14 \$ 1.00$

Volume 73, January 1984, 134-147 of gentamicin, mitochondria isolated from the renal cortex of group 2 rats had significantly higher rates of respiration supported by pyruvate-malate, succinate and $N, N, N^{\prime}, N^{\prime}-$ tetramethyl-p-phenyldiamine-ascorbate, higher rates of dinitrophenol-uncoupled respiration and greater acceptor control ratios than those measured in mitochondria isolated from the renal cortex of group 1 animals. Similarly, after 8 and 10 doses, renal cortex and renal cortical mitochondrial $\mathrm{Ca}^{++}$content of group 2 was significantly lower than values observed in group 1 . Thus, dietary calcium supplementation significantly protected against gentamicin-induced renal tubular cell injury and, consequently, gentamicin-induced acute renal failure.

The mechanism for this protective effect of $\mathrm{Ca}^{++}$may relate to the manner in which this polycationic antibiotic interacts with anionic sites, primarily the acidic phospholipids of renal membranes. In this regard, $\mathrm{Ca}^{++}$was found to be a competitive inhibitor both of ${ }^{125} \mathrm{I}$-gentamicin binding to renal brush border membranes, the initial site of interaction between gentamicin and renal proximal tubule cells, with a composite inhibition constant $\left(K_{\mathrm{i}}\right)$ of $12 \mathrm{mM}$ and of ${ }^{125}$ I-gentamicin binding to phosphatidic acid, an important membrane acidic phospholipid, with a $K_{\mathrm{i}}$ of $170 \mu \mathrm{M}$. Dietary calcium supplementation, however, did not alter either peak renal cortical gentamicin levels or the time course to achieve peak levels compared with animals receiving gentamicin and normal diets, suggesting that the mechanism of $\mathrm{Ca}^{++}$protection may not be related only to an inhibition of gentamicin binding to and uptake along the plasma membrane of the renal tubule cell. Instead, studies of maneuvers that alter the severity of gentamicin nephrotoxicity suggest that $\mathrm{Ca}^{++}$ loading may protect against gentamicin-induced renal tubular cell injury by preventing critical gentamicin-membrane interactions within the renal tubular cell. Placing rats on sodium-supplemented and sodium-deficient diets 
ameliorated and potentiated gentamicin nephrotoxicity, respectively. Sodium bicarbonate supplementation was no better than an equimolar supplementation with sodium chloride in ameliorating gentamicin nephrotoxicity, suggesting that the protective effect of $\mathrm{CaCO}_{3}$ appears to reside in $\mathrm{Ca}^{++}$and not the alkalinizing anion. Calcium supplementation was protective against gentamicin-induced excretory failure and renal cell injury in the presence of volume depletion produced with sodium-deficient diets but lost its protective effect in the presence of volume expansion produced with $\mathrm{NaCl}$-supplemented diets. Since $\mathrm{Ca}^{++}$flux across the proximal tubule cell is enhanced during volume depletion and depressed during volume expansion, these results are consistent with the view that a critical level of transport of $\mathrm{Ca}^{++}$, perhaps as a competitive inhibitor to modify gentamicin interactions with critical subcellular membranes, is required for the protective effect of $\mathrm{Ca}^{++}$. Thus, $\mathrm{Ca}^{++}$is an effective competitive inhibitor of gentamicin-renal membrane binding interactions, and oral calcium loading significantly protects against the later stages of gentamicin nephrotoxicity perhaps by the action of $\mathrm{Ca}^{++}$to inhibit detrimental effects of gentamicin at critical subcellular membrane sites of the renal proximal tubule cell.

\section{Introduction}

A recent study by Bennett and co-workers (1) has demonstrated that dietary calcium supplementation substantially ameliorated gentamicin-induced acute renal failure, as measured by serum creatinine and inulin clearance. Since renal excretory function may decline either from functional hemodynamic alterations or from structural renal tubular cell injury, it is presently unclear whether this protection results from less severe functional or less severe structural alterations within the kidney. In this regard, study of the pathogenesis of acute renal failure, particularly the study of differentiation between the relative contribution of functional nephronal events, such as altered glomerular blood flow and permeability, vs. the contribution of direct tubule cell injury, has long been hampered by the fact that cell injury in both toxic and ischemic acute renal failure as a rule is heterogeneous, affecting some types of tubule cells but not others. There have been few good methods applied to quantify the extent of tubule cell injury other than morphologic studies, which are prone to sampling errors, fixation artifacts, and grading difficulties. Evidence increasingly suggests that a variety of biochemical indices critical in developing cell injury, including renal cortical mitochondrial function and renal cortex and mitochondrial calcium content, can be useful quantitative indices of cell injury and correlate well with the degree of renal excretory failure (2-5). Accordingly, experiments were undertaken in this study to determine if dietary calcium loading protects against gentamicin nephrotoxicity by ameliorating the degree of renal tubule cell injury produced by this antibiotic.

The mechanism by which dietary calcium supplementation ameliorates gentamicin nephrotoxicity is presently unclear. Since gentamicin-induced plasma and subcellular membrane injury appear to be critical pathogenetic events in gentamicin nephrotoxicity (6-8), $\mathrm{Ca}^{++}$may be altering the manner in which gentamicin interacts with renal cellular membranes. In this regard, multiple binding sites for the aminoglycoside antibiotics have been characterized in a variety of membranes (9-13). For developing toxicity, the high affinity site is most critical and has been recently identified as the acidic phospholipids of the membrane $(9,10)$. This binding reaction is due to a charge interaction between these polycationic antibiotics and the anionic head groups of acidic phospholipids. Not surprisingly, a number of studies have demonstrated that the divalent cations, calcium and magnesium, interfere with a large number of membraneaminoglycoside interactions, including effects of aminoglycosides at artificial membranes (14), bacterial membranes (15), plasma membranes (16-20), and subcellular membranes (21-23). Accordingly, the protective effect provided by $\mathrm{Ca}^{++}$on gentamicin nephrotoxicity may relate to its ability to inhibit critical gentamicin-renal membrane interactions. To assess this possibility, experiments were carried out to determine and characterize the manner in which $\mathrm{Ca}^{++}$and $\mathrm{Mg}^{++}$affect gentamicin binding to both renal brush border membranes (BBMs), ${ }^{1}$ the initial site of interaction between aminoglycosides and renal proximal tubule cells, and phosphatidic acid, an acidic phospholipid which is the central precursor of the metabolically active pool of acidic phospholipids within the membrane.

In summary, this series of experiments was undertaken to examine a number of issues: $(a)$ to better characterize the reported effect of dietary calcium loading to protect against gentamicin-induced acute renal failure, $(b)$ to establish the extent to which this protection is based upon amelioration of the degree of gentamicin-induced renal tubule cell injury measured by several critical biochemical parameters related to cell injury, and (c) to test whether this protective effect could be due to the ability of $\mathrm{Ca}^{++}$to act as a competitive inhibitor of gentamicinrenal membrane interactions either at the cell surface or subcellular sites of the renal proximal tubule cell.

\section{Methods}

\section{Membrane isolation}

Renal BBMs were isolated by the divalent cation precipitation technique detailed previously $(9,24)$. Magnesium was used as the precipitating divalent cation for those experiments testing the effect of calcium as an inhibitor of ${ }^{125}$ I-gentamicin binding to BBMs. Calcium was used as the precipitating cation for experiments testing magnesium as an inhibitor

1. Abbreviations used in this paper: ACR, acceptor control ratio; BBM, brush border membrane; BUN, blood-urea nitrogen; DNP, 2,4-dinitrophenol; PTH, parathyroid hormone; RR, ruthenium red; TMPD, $N, N, N^{\prime}, N^{\prime}$-tetramethyl-p-phenylenediamine. 
of the binding interaction. Marker enzyme assays demonstrated no difference between these two procedures on the purity of membrane preparation. The BBM to homogenate ratio for the BBM enzyme, alkaline phosphatase was 8.0; the ratio for the basolateral enzyme, Na-K-ATPase, was 0.4; the ratio for the endoplasmic reticulum enzyme, NADPH cytochrome $\mathrm{c}$ reductase, was $\leq 0.1$; the ratio for the lysosomal enzyme, $N$-acetyl- $\beta$-D-glucosaminidase, was 0.15 ; the ratio for the mitochondrial enzyme, cytochrome $c$ oxidase, was $\leq 0.1$. These values are similar to our previous reports $(9,24)$ and indicate substantial purity of the BBM fraction.

\section{${ }^{125}$ I-Gentamicin binding assays}

${ }^{125} \mathrm{I}-$ Gentamicin binding to isolated renal BBMs and to the acidic phospholipid, phosphatidic acid, were done by the same procedures described in detail in a previous report (9). BBMs were added to an assay buffer solution containing 25 or $50 \mu \mathrm{M}^{125}$ I-gentamicin with or without 1,000 fold excess unlabeled gentamicin and were incubated for $60 \mathrm{~min}$ at $37^{\circ} \mathrm{C}$. Nonspecific binding was $<10 \%$ of total binding in these experiments. The effect of calcium and magnesium on binding was assessed by adding various concentrations of the divalent cations to the assay buffer simultaneously to the addition of the radioligand.

\section{Renal cortical gentamicin levels}

Samples from renal cortical homogenates were frozen and thawed at least twice, diluted $1: 100$ with $0.15 \%$ Triton- $X$ in water and gentamicin levels in these diluted specimens were determined by a standard radioimmunoassay method (New England Nuclear, Boston, MA).

\section{Mitochondrial isolation}

Isolated renal cortical mitochondria were prepared using a procedure similar to that which we have used previously $(25,26)$. Male SpragueDawley rats were killed by cervical dislocation. Both kidneys were rapidly removed and placed in ice-cold $0.27 \mathrm{M}$ sucrose. From this point until testing of the final mitochondrial preparations all procedures were carried out at $4^{\circ} \mathrm{C}$. After the capsule and perirenal fat were removed, the kidneys were longitudinally divided and the cortices were dissected. Both renal cortices were coarsely minced. The tissue was homogenized in a PotterElvehjem homogenizer with a Teflon pestle (Arthur H. Thomas Co., Philadelphia, PA; size BB), with a homogenizing solution consisting of $0.27 \mathrm{M}$ sucrose, $1 \mathrm{mM}$ EGTA, and $5 \mathrm{mM}$ Tris- $\mathrm{HCl}, \mathrm{pH} \mathrm{7.4,} \mathrm{and} 20$ $\mu \mathrm{M}$ ruthenium red (RR), a potent specific inhibitor of mitochondrial calcium uptake. The tissue weight to volume ratio ranged between 1:15 and 1:10. The renal cortical homogenates were centrifuged for $10 \mathrm{~min}$ at $600 \mathrm{~g}$ in a model RC2 Sorvall refrigerated centrifuge. The supernatants were decanted and then centrifuged again at $10,000 \mathrm{~g}$ for $5 \mathrm{~min}$. The resulting mitochondrial pellets were then resuspended in $10 \mathrm{ml}$ of wash solution containing $0.27 \mathrm{M}$ sucrose and $30 \mu \mathrm{M}$ EGTA and centrifuged at $10,000 \mathrm{~g}$ for $5 \mathrm{~min}$. The supernatants were discarded and the pellets resuspended in $3 \mathrm{ml}$ of wash solution. The wash solutions contained $30 \mu \mathrm{M}$ EGTA to chelate the small amount of contaminating $\mathrm{Ca}^{++}$in the sucrose in order to further minimize $\mathrm{Ca}^{++}$interactions with mitochondria. All functional studies were done on freshly isolated mitochondria within $2 \mathrm{~h}$ of their isolation.

\section{Measurement of mitochondrial respiration}

Oxygen consumption was measured polarographically at $30^{\circ} \mathrm{C}$ in a closed 1.4-ml vessel with stirring bar and thermostatically controlled bath (model K-1C, Gilson Medical Electronics, Inc., Middleton, WI). The incubation medium for measuring mitochondrial respiration consisted of $130 \mathrm{mM}$ $\mathrm{KCl}, 9 \mathrm{mM}$ Tris- $\mathrm{PO}_{4}, \mathrm{pH} \mathrm{7.3,} 4 \mathrm{mM}$ Tris- $\mathrm{HCl}, \mathrm{pH} \mathrm{7.3}$, and $1 \mathrm{mM}$ EGTA. Respiratory substrates for individual experiments consisted of either sodium pyruvate $(5 \mathrm{mM})$-sodium malate $(5 \mathrm{mM})$, or sodium succinate $(10 \mathrm{mM})$, or sodium ascorbate $(10 \mathrm{mM})-N, N, N^{\prime}, N^{\prime}$-tetramethylp-phenylenediamine $(0.3 \mathrm{mM})$. In studies where succinate was the respiratory substrate, $10 \mu \mathrm{M}$ rotenone was present. In studies with TMPDascorbate as substrate, $10 \mu \mathrm{M}$ rotenone and $0.80 \mu \mathrm{g} / \mathrm{ml}$ of antimycin were present. Each experiment was started by adding $0.6-0.7 \mathrm{mg}$ of mitochondrial protein to the oxygraph cell containing incubation medium and substrate. At $3 \mathrm{~min}$ after the addition of mitochondria, $400 \mathrm{nmol}$ of ADP was added to initiate state 3 respiration. State 4 respiration was measured as the slower respiratory rate following depletion of the added ADP. In experiments where 2,4-dinitrophenol (DNP)-uncoupled respiratory rates were tested, DNP was added during stable state 4 respiration as $10 \mu \mathrm{l}$ of an absolute ethanol solution to produce a final concentration of $100 \mu \mathrm{M}$. Oxygen consumption calculations are based on an oxygen solubility in the buffer exposed to room air at $25^{\circ} \mathrm{C}$ of 474 nanoatom equivalents of oxygen per milliliter and respiratory rates are reported as nanoatom equivalents of oxygen consumed per milligram of mitochondrial protein per minute.

\section{Measurement of renal cortical homogenate and mitochondrial calcium content}

Samples from renal cortical homogenates and renal cortical mitochondria were stored in dry plastic tubes previously rinsed with dilute $\mathrm{HCl}$. Samples were frozen and thawed at least twice before calcium content was determined. Calcium measurements were done on an Atomic Absorption Spectrophotometer (model 306; Perkin-Elmer Corp., Norwalk, CT) and were determined on 1:50 and 1:25 dilutions of homogenates and mitochondria, respectively. All samples and standards were diluted in a solution made by adding $11.7 \mathrm{~g} \mathrm{La}_{2} \mathrm{O}_{3}$ and $50 \mathrm{ml}$ of concentrated $\mathrm{HCl}$ to deionized, glass-distilled water to a volume of $1,000 \mathrm{ml}$. Acationox (Scientific Products Inc., Detroit, MI), a detergent with extremely low cation content, was added to all dilutions to a concentration of $0.0125 \%$. All dilutions were done in dry plastic tubes previously rinsed with dilute $\mathrm{HCl}$. Electrolyte levels obtained are reported as nanomoles per milligram of homogenate or mitochondrial protein. The validity of these measurements has been established in a previous report (3).

\section{Experimental groups}

Male Sprague-Dawley rats weighing between 250-325 g were used for all studies. Rats treated with gentamicin received daily injections of the antibiotic, $100 \mathrm{mg} / \mathrm{kg}$ body weight, in the morning. The animals were killed $24 \mathrm{~h}$ after the last dose of gentamicin. All rats had free access to food and water during the entire treatment course. Special diets were begun the day before initiating gentamicin injections.

Group 1. Rats in this group ingested standard rat chow 5012 (Ralston Purina Co., St. Louis, MO) containing $0.36 \%$ sodium and $0.9 \%$ calcium by weight.

Group 2. Rats in this group ingested standard rat chow supplemented with $4 \%$ calcium in the form of calcium carbonate $\left(\mathrm{CaCO}_{3}\right)$.

Group 3. Rats in this group ingested standard rat chow and received eight doses of gentamicin.

Group 4. Rats in this group ingested standard rat chow supplemented with $4.6 \%$ sodium in the form of $\mathrm{NaCl}$ and received eight doses of gentamicin. Rats were killed after eight doses because preliminary experiments demonstrated that 10 doses resulted in a high mortality rate from the combination of progressive renal insufficiency and volume overload.

Group 5. Rats in this group ingested standard rat chow supplemented with $4.6 \%$ sodium $(\mathrm{NaCl})$ and $4 \%$ calcium $\left(\mathrm{CaCO}_{3}\right)$ and received eight doses of gentamicin.

Group 6. Rats in this group ingested standard rat chow supplemented 
with $4.6 \%$ sodium in the form of $\mathrm{NaHCO}_{3}$ and received eight doses of gentamicin. This amount of $\mathrm{NaHCO}_{3}$ gave an equivalent alkali load as $4 \% \mathrm{Ca}$ as $\mathrm{CaCO}_{3}$ per gram weight of diet, assuming two $\mathrm{HCO}_{3}^{-}$ions were equivalent to one $\mathrm{CO}_{3}^{-2}$ ion.

Group 7. Rats in this group ingested standard rat chow and received six doses of gentamicin.

Group 8. Rats in this group ingested a sodium-deficient diet (ICN Nutritional Biochemicals, St. Louis, MO) that contained $0.7 \%$ calcium and received six doses of gentamicin.

Group 9. Rats in this group ingested a sodium-deficient diet supplemented with $4 \%$ calcium $\left(\mathrm{CaCO}_{3}\right)$ and received six doses of gentamicin.

\section{Reagents}

All organic reagents were obtained from Sigma Chemical Co. (St. Louis, $\mathrm{MO}$ ) and were of the highest purity available. All other chemicals were reagent grade.

\section{Protein determinations}

Protein concentrations were done by the Lowry method (27) with bovine serum albumin as standard.

\section{Statistical analysis}

Unpaired and paired $t$ tests, as appropriate, were used for statistical analysis of the data. Statistical significance was considered to be $P$ $<0.05$, two tailed.

\section{Results}

\section{Effect of divalent cations on ${ }^{125}$ I-gentamicin binding}

Increasing concentrations of both calcium and magnesium diminished ${ }^{125}$ I-gentamicin binding to isolated renal BBMs (Fig. 1). Calcium was more effective than magnesium in competing for binding sites. Dixon plots of these inhibitory effects (Fig. 2) demonstrated that both calcium and magnesium were competitive inhibitors of this binding reaction with an inhibition

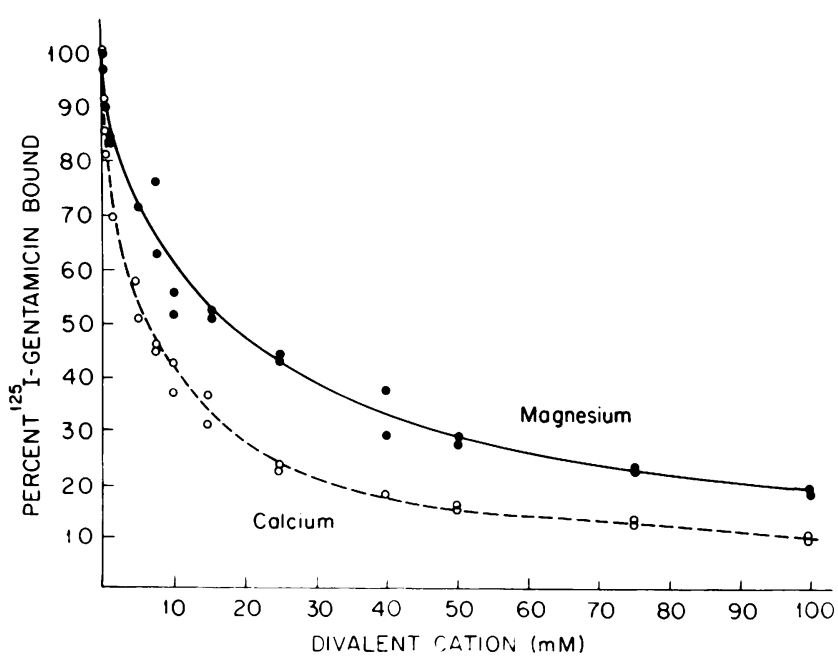

Figure 1. Effect of calcium and magnesium on ${ }^{125}$ I-gentamicin binding to isolated renal BBMs. A concentration of $50 \mu \mathrm{M}^{125} \mathrm{I}$ gentamicin was used.
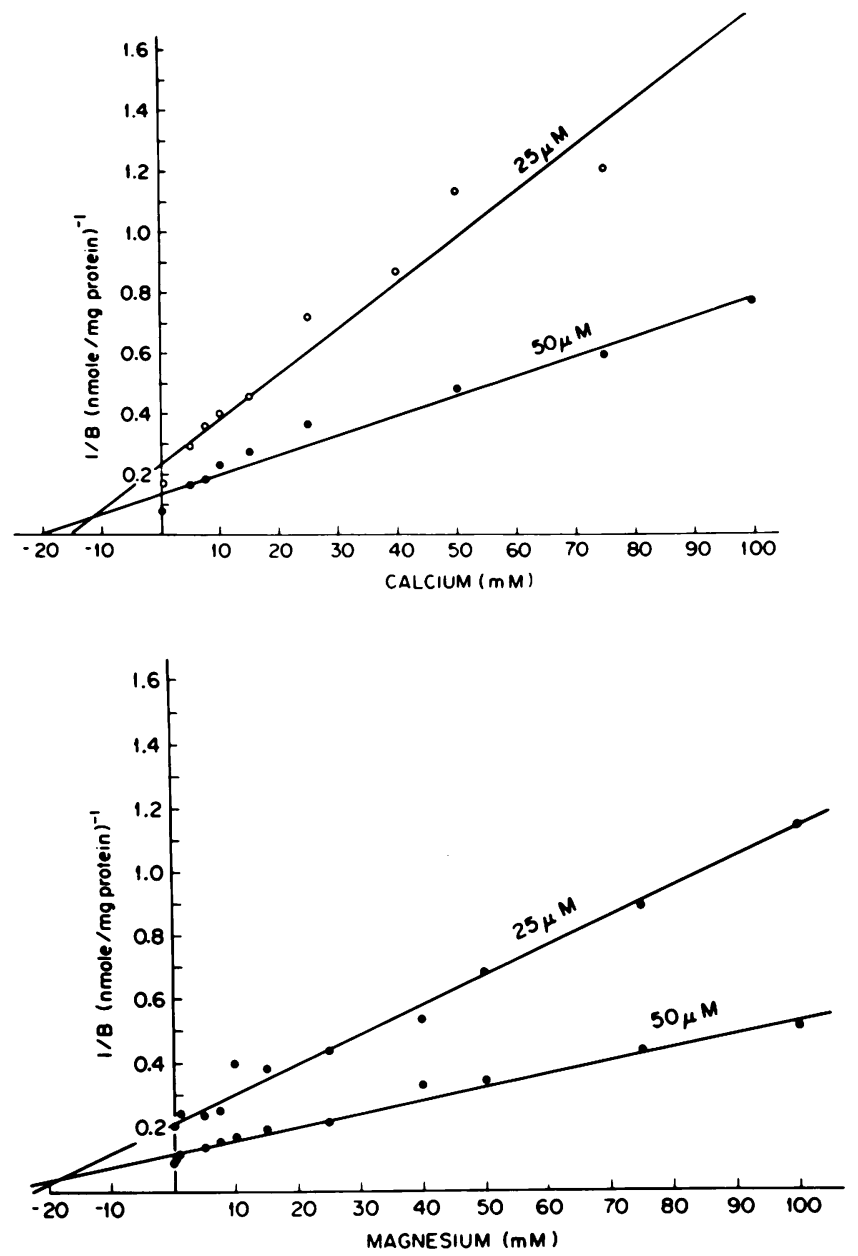

Figure 2. Dixon plots of the effect of calcium (top) and magnesium (bottom) on 25 and $50 \mu \mathrm{M}^{125}$ I-gentamicin binding to isolated renal BBMs. B, amount of bound gentamicin.

constant $\left(K_{\mathrm{i}}\right)$ of $12 \mathrm{mM}$ for calcium and a $K_{\mathrm{i}}$ of $21 \mathrm{mM}$ for magnesium.

Since the acidic phospholipids are the high affinity membrane binding sites for gentamicin, the effect of calcium on ${ }^{125}$ I-gentamicin binding to the acidic phospholipid, phosphatidic acid, in a water/organic solvent partitioning system was assessed. Calcium inhibited this binding reaction (Fig. 3 ) in a competitive manner, as demonstrated by a Dixon plot (Fig. 4) with a $K_{\mathrm{i}}$ of $170 \mu \mathrm{M}$. These findings suggest that calcium can act as a competitive inhibitor of gentamicin-phospholipid binding in a variety of membrane systems.

Effect of dietary calcium supplementation on gentamicininduced nephrotoxicity

Renal excretory function. Fig. 5 displays the time course of blood-urea nitrogen (BUN) levels during the nephrotoxic series of gentamicin injections in groups 1 and 2. Calcium supplementation (group 2) substantially ameliorated the degree of renal 


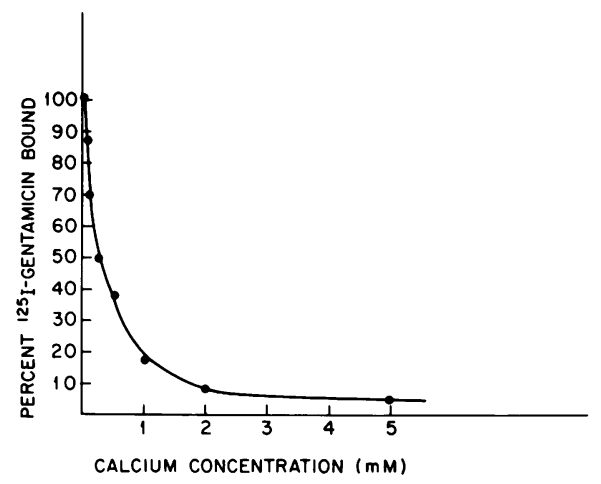

Figure 3. Effect of calcium on ${ }^{125}$ I-gentamicin binding to phosphatidic acid in an aqueous/organic solvent partitioning system A concentration of $25 \mu \mathrm{M}^{125}$ I-gentamicin was used.

excretory failure induced by gentamicin, as assessed by BUN. BUN values averaged $18 \pm 1$ (SEM) and $14 \pm 0.2$ after two doses, $21 \pm 0.4$ and $16 \pm 0.7(P<0.01)$ after four doses, $36 \pm 6$ and $27 \pm 5$ $(P<0.001)$ after six doses, $120 \pm 20$ and $41 \pm 17(P<0.02)$ after eight doses, and $213 \pm 15$ and $25 \pm 3(P<0.001)$ after 10 doses for groups 1 and 2 animals, respectively.

Renal cortical mitochondrial respiratory function. Renal cortical mitochondria, like those from other tissues, avidly transport calcium into their matrices (28). Mitochondria may thus gain calcium during their isolation. Since increases in mitochondrial calcium content may be detrimental to mitochondrial function (8), the use of methods that attempt to limit calcium uptake during the mitochondrial isolation procedure is critical in obtaining a mitochondria preparation in vitro reflective of mitochondrial function in situ. In this regard, a homogenizing solution containing both $1 \mathrm{mM}$ EGTA, an avid

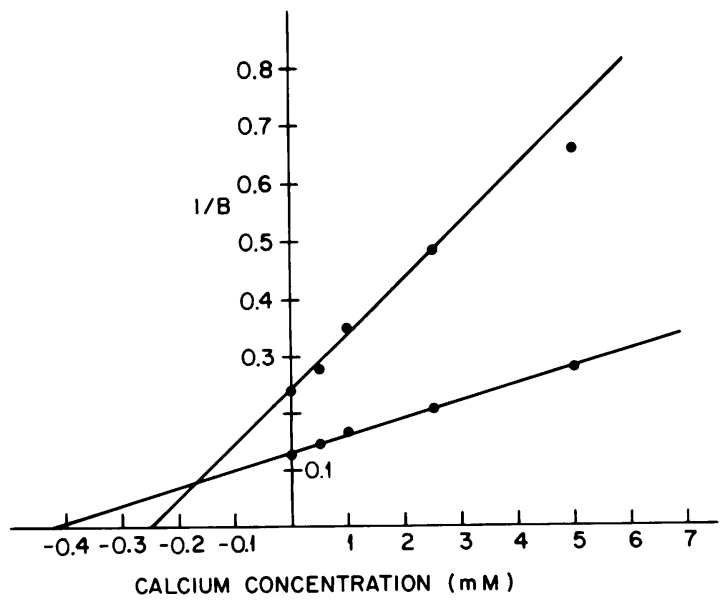

Figure 4. Dixon plot of the effect of calcium on $25 \mu \mathrm{M}$ (top line) and $50 \mu \mathrm{M}$ (bottom line) ${ }^{125} \mathrm{I}$-gentamicin binding to phosphatidic acid in the aqueous/organic solvent partitioning system. B, the amount of bound gentamicin.

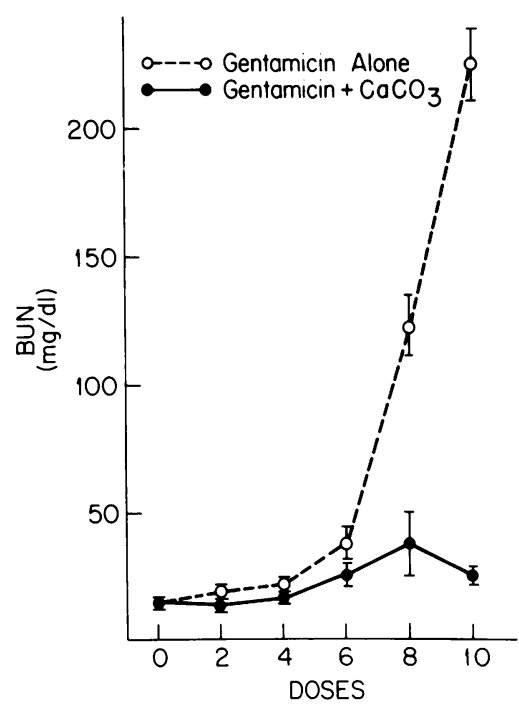

Figure 5. Time course of BUN elevations ater increasing daily doses of gentamicin $(100 \mathrm{mg} / \mathrm{kg})$ in rats on standard (group 1, gentamicin alone) and 4\% calcium-supplemented (group 2, gentamicin plus $\mathrm{CaCO}_{3}$ ) diets.

calcium chelator, and $20 \mu \mathrm{M} R \mathrm{R}$, a potent mitochondrial $\mathrm{Ca}^{++}$uptake inhibitor, and a wash solution containing $30 \mu \mathrm{M}$ EGTA were used in this study. Homogenizing solutions containing 1 mM EGTA but not RR are the standard buffers used in our previous studies to prevent $\mathrm{Ca}^{++}$uptake by mitochondria when low levels of homogenate $\mathrm{Ca}^{++}$are present. In severe injury states, when cellular $\mathrm{Ca}^{++}$overload is substantial, enough homogenate $\mathrm{Ca}^{++}$may be present to overwhelm the chelating capability of $1 \mathrm{mM}$ EGTA so that large amounts of free $\mathrm{Ca}^{++}$ may be available for mitochondrial uptake. The addition of RR in this study effectively inhibits $\mathrm{Ca}^{++}$uptake in this situation (29) and prevents artifactual declines in mitochondrial function that may occur during the isolation procedure.

Table I summarizes all mitochondrial respiratory data from animals on standard diets (group 1) and on calcium-supplemented diets (group 2). Compared with values of mitochondria obtained from control rats, gentamicin treatment resulted in renal cortical mitochondrial respiratory alterations after as few as four doses of gentamicin. After four doses, all respiratory values were significantly different from control in both groups 1 and 2 except for succinate-state 4 and TMPD-ascorbate in group 1 and succinate-state 3 , succinate-acceptor control ratio (ACR) in group 2. No consistent differences between the two groups were present after either two or four doses. After six doses, all group 1 respiratory values were significantly different compared with control for all substrates. In group 2, all values except state 4 respiratory values were significantly altered compared to control.

As progressive renal cell injury developed, calcium supplementation was associated with lesser degrees of gentamicininduced renal cortical mitochondrial dysfunction (Table I and 
Table I. Effects of Gentamicin Treatment on Basic Respiratory Parameters of Renal Cortical Mitochondria Isolated from Rats on Standard or 4\% Calcium-supplemented Diets

\begin{tabular}{|c|c|c|c|c|c|c|c|c|c|c|}
\hline \multirow[b]{2}{*}{ Doses } & \multirow[b]{2}{*}{$n$} & \multicolumn{4}{|c|}{ Pyruvate-malate } & \multicolumn{4}{|c|}{ Succinate } & \multirow{2}{*}{$\begin{array}{l}\text { TMPD- } \\
\text { ascorbate }\end{array}$} \\
\hline & & S3 & $\$ 4$ & ACR & DNP & S3 & S4 & ACR & DNP & \\
\hline \multirow[t]{2}{*}{ Control } & 8 & 150 & 37 & 4.08 & 94 & 356 & 100 & 3.57 & 348 & 444 \\
\hline & & \pm 8 & \pm 3 & \pm 0.13 & \pm 6 & \pm 17 & \pm 4 & \pm 0.05 & \pm 15 & \pm 35 \\
\hline \multicolumn{11}{|l|}{2} \\
\hline \multirow[t]{2}{*}{ Group 1} & 4 & 129 & 35 & 3.74 & 74 & 299 & 88 & 3.40 & 309 & 353 \\
\hline & & \pm 6 & \pm 2 & \pm 0.05 & \pm 6 & \pm 9 & \pm 5 & \pm 0.08 & \pm 9 & \pm 13 \\
\hline \multirow[t]{2}{*}{ Group 2} & 4 & 140 & 37 & 3.82 & 80 & 328 & 97 & 3.38 & 354 & 404 \\
\hline & & \pm 8 & \pm 2 & \pm 0.16 & \pm 6 & \pm 17 & \pm 3 & \pm 0.09 & \pm 17 & \pm 7 \\
\hline \multicolumn{11}{|l|}{4} \\
\hline \multirow[t]{2}{*}{ Group 1} & 4 & 114 & 34 & 3.41 & 69 & 247 & 88 & 2.83 & 262 & 349 \\
\hline & & \pm 6 & \pm 2 & \pm 0.03 & \pm 3 & \pm 9 & \pm 7 & \pm 0.06 & \pm 11 & \pm 16 \\
\hline \multirow[t]{2}{*}{ Group 2} & 4 & 123 & 34 & 3.62 & 74 & 274 & 91 & 3.08 & 302 & 360 \\
\hline & & \pm 8 & \pm 2 & \pm 0.16 & \pm 5 & \pm 27 & \pm 10 & \pm 0.10 & \pm 28 & \pm 37 \\
\hline \multicolumn{11}{|l|}{6} \\
\hline \multirow[t]{2}{*}{ Group 1} & 4 & 83 & 26 & 3.12 & 47 & 176 & 73 & 2.40 & 197 & 246 \\
\hline & & \pm 7 & \pm 2 & \pm 0.08 & \pm 5 & \pm 15 & \pm 5 & \pm 0.12 & \pm 15 & \pm 29 \\
\hline \multirow[t]{2}{*}{ Group 2} & 4 & 116 & 32 & 3.57 & 65 & 230 & 89 & 2.60 & 250 & $321^{*}$ \\
\hline & & \pm 8 & \pm 2 & \pm 0.08 & \pm 5 & \pm 19 & \pm 9 & \pm 0.07 & \pm 13 & \pm 21 \\
\hline \multicolumn{11}{|l|}{8} \\
\hline \multirow[t]{2}{*}{ Group 1} & 6 & 68 & 24 & 2.72 & 40 & 136 & 64 & 2.11 & 159 & 230 \\
\hline & & \pm 10 & \pm 2 & \pm 0.26 & \pm 5 & \pm 14 & \pm 4 & \pm 0.16 & \pm 16 & \pm 23 \\
\hline \multirow[t]{2}{*}{ Group 2} & 6 & $110 \ddagger$ & 33 & 3.38 & $71 \S$ & $224 \S$ & $90 \ddagger$ & 2.48 & $258 \S$ & $325^{*}$ \\
\hline & & \pm 9 & \pm 4 & \pm 0.13 & \pm 6 & \pm 20 & \pm 7 & \pm 0.06 & \pm 22 & \pm 22 \\
\hline \multicolumn{11}{|l|}{10} \\
\hline \multirow[t]{2}{*}{ Group 1} & 5 & 47 & 22 & 2.17 & 22 & 111 & 60 & 1.86 & 130 & 173 \\
\hline & & \pm 4 & \pm 1 & \pm 0.26 & \pm 2 & \pm 7 & \pm 8 & \pm 0.10 & \pm 9 & \pm 16 \\
\hline \multirow[t]{2}{*}{ Group 2} & 6 & $97^{11}$ & $31 \ddagger$ & $3.18 \ddagger$ & $58^{\prime \prime}$ & $190^{\prime \prime}$ & $81^{11}$ & $2.37 \S$ & $211 \S$ & $242 \ddagger$ \\
\hline & & \pm 4 & \pm 2 & \pm 0.17 & \pm 3 & \pm 5 & \pm 4 & \pm 0.06 & \pm 3 & \pm 8 \\
\hline
\end{tabular}

Group 1 rats received a standard diet; group 2 rats received a standard diet supplemented with $4 \%$ calcium. Respiratory rates are given as mean nanoatom equivalents of oxygen per milligram protein per minute \pm SEM. $n$ indicates number of animals in each group. Significant differences relative to controls are discussed in text.

* $P<0.05$ (group 2 relative to group 1 ).

$\ddagger P<0.02$ (group 2 relative to group 1 ).

$\S P<0.01$ (group 2 relative to group 1).

" $P<0.001$ (group 2 relative to group 1 ).

Fig. 6). After six doses, respiration supported by TMPD-ascorbate was better preserved in group 2 compared with group 1. After eight doses, most respiratory values were better in the calcium-

supplemented group than in the standard diet group. And after 10 doses, all mitochondrial respiratory parameters were protected by calcium supplementation.

Renal cortical homogenate and mitochondrial calcium contents. Since dying cells lose their ability to control intracellular calcium within normally low levels, injured cells develop progressive degrees of calcium overload, so that tissue calcium content reflects the degree of cell necrosis $(2,3,7,8)$. In this regard, 

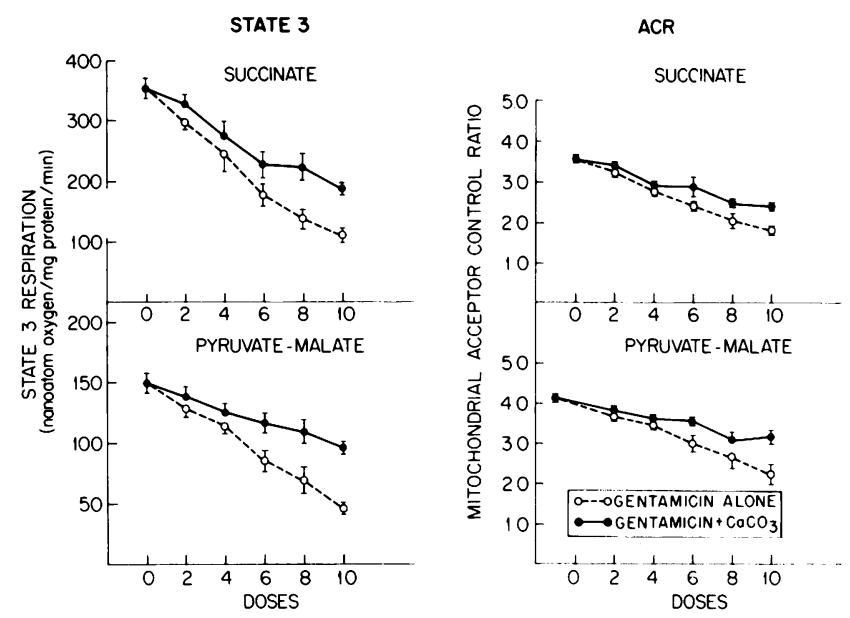

Figure 6. Time course of renal cortical mitochondrial state 3 respiration and acceptor control ratio with increasing daily doses of gentamicin in rats on standard (group 1, gentamicin alone) and 4\% calcium-supplemented (group 2, gentamicin plus $\mathrm{CaCO}_{3}$ ) diets.

renal cortical homogenate calcium content was significantly higher in group 1 animals compared with group 2 rats on a calcium-supplemented diet along the entire time course of the nephrotoxic series of injections (Table II). Fig. 7 demonstrates that the decline in renal excretory function, as measured by a rise in BUN, correlated well with renal cell injury, as measured by renal cortical homogenate calcium content, in groups 1 and 2 after 10 doses with an $r$ value of 0.86 . Furthermore, the values segregated into two distinctly different populations strictly dependent on whether they were calcium loaded or not. All group 1 animals had BUNs $>50 \mathrm{mg} / \mathrm{dl}$ and renal cortical homogenate calcium contents $\geq 25 \mathrm{nmol} / \mathrm{mg}$ protein; all group 2 rats had BUNs $<50 \mathrm{mg} / \mathrm{dl}$ and calcium contents $\leq 25 \mathrm{nmol} / \mathrm{mg}$ protein.

The values for homogenate calcium content were reflective of cellular calcium overload, since they rose in parallel to the increases in renal cortical mitochondrial calcium content (Table II, Fig. 8). Mitochondrial calcium content was significantly higher in group 1 compared with group 2 after both 8 and 10 doses. Calcium supplementation tended to increase total serum calcium levels, but only after two doses were these increases in serum calcium concentrations of group 2 significantly higher than that of group 1 (Table II).

Renal cortical gentamicin levels. Table III displays the gentamicin levels in renal cortex from group 1 and 2 rats. No difference between levels was found between groups during the entire time course.

\section{Effect of dietary sodium manipulations on the protection} afforded by calcium

Maneuvers to alter the severity of gentamicin nephrotoxicity were studied to gain further insight into the mechanism of gentamicin-induced renal tubular cell injury and the mechanism by which $\mathrm{Ca}^{++}$loading may protect against gentamicin neph- rotoxicity. Since alterations in sodium balance have been shown to modify gentamicin nephrotoxicity (30), the effects on the course of gentamicin nephrotoxicity of volume expansion produced by dietary $\mathrm{NaCl}$ supplementation (group 4) and volume depletion produced by dietary sodium deprivation (group 8) were assessed. Furthermore, the influence of these sodium dietary manipulations on the protective effect afforded by oral calcium loading was also determined. Since $\mathrm{Ca}^{++}$and $\mathrm{Na}^{+}$transepithelial transport are intimately linked in the proximal tubule (so that increased $\mathrm{Na}^{+}$reabsorption in sodium-depleted states is accompanied by higher $\mathrm{Ca}^{++}$reabsorptive rates, and diminished $\mathrm{Na}^{+}$ reabsorption in sodium-loaded states is associated with lower $\mathrm{Ca}^{++}$reabsorptive rates) $\mathrm{Ca}^{++}$flux across the proximal tubule cell can be modulated by dietary sodium manipulation (31). Groups of rats on calcium-supplemented diets were, therefore, placed on $\mathrm{NaCl}$-supplemented (group 5) and sodium-deficient (group 9) diets to determine whether modifying transcellular flux of $\mathrm{Ca}^{++}$across the proximal tubule cell by sodium balance manipulations influences the protection afforded by $\mathrm{Ca}^{++}$on gentamicin nephrotoxicity. Finally, since alkali loading with $\mathrm{HCO}_{3}^{-}$has been suggested to ameliorate gentamicin nephrotoxicity (32), the effect of $\mathrm{NaHCO}_{3}$ supplementation (group 6) on gentamicin-induced renal excretory failure and renal cell injury was assessed to determine whether the alkali load, rather than $\mathrm{Ca}^{++}$, was responsible for the protective effect of $\mathrm{CaCO}_{3}$ dietary supplementation.

Renal excretory function. Sodium loading with oral $\mathrm{NaCl}$ (group 4) protected from gentamicin-induced declines in renal excretory function, as measured by BUN (Table IV). After eight doses, BUN from group 4 averaged $51 \pm 4$, a value significantly lower $(P<0.001)$ than the value of $120 \pm 20 \mathrm{mg} / \mathrm{dl}$ from group 3 animals, who were on standard diets. Calcium supplementation did not further protect sodium-loaded animals, since the BUN values of group 5 animals were no different from those of group 4 rats. Furthermore, dietary supplementation with sodium in

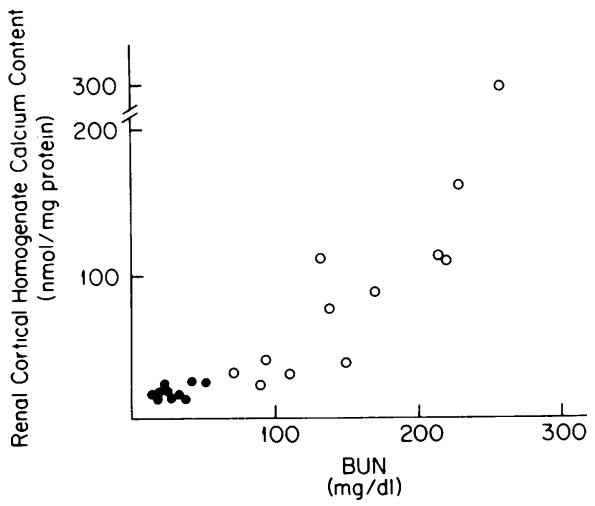

Figure 7. Correlation between renal excretory failure, as measured by BUN, and renal cell injury, as measured by renal cortical homogenate calcium content, in group 1 rats on standard diets $(O)$ and in group 2 rats on calcium-supplemented diets $(\bullet)$ after 10 doses of gentamicin. 
Table II. Serum Calcium Concentration and Calcium Content of Renal Cortical Homogenates and Mitochondria from Rats Treated with Gentamicin and Ingesting Standard or Calcium-supplemented Diets

\begin{tabular}{|c|c|c|c|c|c|c|}
\hline Doses & Control & 2 & 4 & 6 & 8 & 10 \\
\hline \multicolumn{7}{|c|}{$\begin{array}{l}\text { Total serum calcium concentration } \\
\qquad(m M)\end{array}$} \\
\hline \multirow[t]{2}{*}{ Group 1} & & 2.45 & 2.42 & 2.89 & 2.86 & 2.97 \\
\hline & 2.46 & \pm 0.02 & \pm 0.16 & \pm 0.16 & \pm 0.05 & \pm 0.45 \\
\hline \multirow[t]{2}{*}{ Group 2} & \pm 0.02 & $2.69^{*}$ & 2.64 & 2.99 & 2.75 & 2.89 \\
\hline & & \pm 0.07 & \pm 0.10 & \pm 0.30 & \pm 0.13 & \pm 0.17 \\
\hline \multicolumn{7}{|c|}{$\begin{array}{l}\text { Homogenate calcium content } \\
\text { (nmol/mg protein })\end{array}$} \\
\hline \multirow[t]{2}{*}{ Group 1} & & 13.1 & 11.4 & 21.0 & 80.2 & 145.0 \\
\hline & 12.3 & \pm 0.8 & \pm 0.5 & \pm 4.4 & \pm 40.3 & \pm 38.9 \\
\hline \multirow[t]{2}{*}{ Group 2} & \pm 0.7 & 11.9 & 12.6 & 14.9 & $25.3^{*}$ & $18.0 \ddagger$ \\
\hline & & \pm 0.7 & \pm 0.6 & \pm 1.2 & \pm 3.3 & \pm 1.2 \\
\hline \multicolumn{7}{|c|}{$\begin{array}{l}\text { Mitochondrial calcium content } \\
\quad(n m o l / m g \text { protein })\end{array}$} \\
\hline \multirow[t]{2}{*}{ Group 1} & & 12.0 & 12.2 & 22.9 & 61.8 & 99.7 \\
\hline & 13.3 & \pm 0.2 & \pm 0.5 & \pm 2.5 & \pm 19.0 & \pm 14.8 \\
\hline \multirow[t]{2}{*}{ Group 2} & \pm 0.8 & 14.8 & 14.1 & 21.9 & $33.2^{*}$ & $28.3 \ddagger$ \\
\hline & & \pm 0.4 & \pm 0.8 & \pm 2.9 & \pm 4.4 & \pm 2.8 \\
\hline
\end{tabular}

Group 1 rats ingested standard diets; group 2 rats ingested 4\% calcium-supplemented diets. $n=4-6$ in each group. Data expressed as means \pm SEM.

$* P<0.05$ relative to group 1 .

$\ddagger P<0.01$ relative to group 1 .

the form of $\mathrm{NaHCO}_{3}$ provided no further protection than supplementation with $\mathrm{NaCl}$ from gentamicin-induced elevations in BUN (group 6 vs. group 4).

Sodium deprivation potentiated gentamicin nephrotoxicity. After six doses, rats on sodium-deficient diets (group 8) had an average BUN of $107 \pm 8$, a value significantly higher $(P<0.001)$

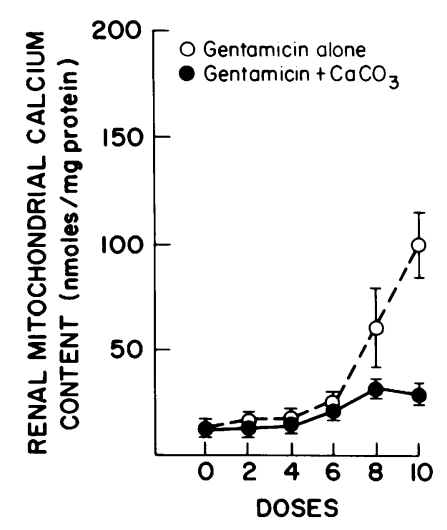

Figure 8. Time course of renal cortical mitochondrial calcium content after increasing daily doses of gentamicin in rats on standard (group 1, gentamicin alone) and $4 \%$ calciumsupplemented (group 2, gentamicin plus $\mathrm{CaCO}_{3}$ ) diets. than the BUN level of $36 \pm 6$ in rats on standard diets (group 7). Calcium loading in the setting of sodium depletion, however, protected against the gentamicin-induced rise in BUN. Animals on sodium-deficient diets receiving calcium supplementation (group 9) had a BUN level of $31 \pm 7$, a value significantly lower $(P<0.001)$ than that of group 8 but no different from that of group 7 . Thus, calcium supplementation ameliorated gentamicin-induced declines in renal excretory function only in sodium depleted but not sodium-loaded animals.

Renal cortical mitochondrial respiratory function. Table $\mathrm{V}$ displays all mitochondrial respiratory parameters for groups 39. After eight doses, sodium supplementation with $\mathrm{NaCl}$ (group 4) ameliorated several, but not all, gentamicin-induced declines in mitochondrial respiratory parameters observed in animals on standard diets (group 3). The addition of $\mathrm{CaCO}_{3}$ to the diet (group 5), however, resulted in no further amelioration than that seen with $\mathrm{NaCl}$ loading alone. Sodium supplementation with $\mathrm{NaHCO}_{3}$ (group 6), however, maintained renal cortical mitochondrial function during developing gentamicin nephrotoxicity much better than $\mathrm{NaCl}$, since all mitochondrial absolute respiratory rates of group 6 animals were significantly better than those from group 3 animals, whereas only the ACRs were significantly higher in group 4 compared with group 3 . Thus, bicarbonate appeared to provide an additional benefit to 
Table III. Renal Cortical Gentamicin Levels in Rats Treated with Gentamicin and Receiving Standard or Calcium-supplemented Diets

\begin{tabular}{lrrrrr}
\hline Doses & \multicolumn{1}{c}{4} & \multicolumn{1}{l}{4} & 6 & \multicolumn{1}{c}{8} & \multicolumn{1}{c}{10} \\
\hline $\begin{array}{l}\text { Gentamicin level } \\
\text { ( } \mu \text { g/mg protein })\end{array}$ & & & & & \\
Group 1 & 7.0 & 8.3 & 7.8 & 6.9 & 7.4 \\
& \pm 0.3 & \pm 1.2 & \pm 0.3 & \pm 0.8 & \pm 0.8 \\
Group 2 & 6.4 & 12.3 & 10.3 & 9.5 & 7.6 \\
& \pm 0.3 & \pm 0.8 & \pm 0.2 & \pm 1.8 & \pm 0.7 \\
\hline
\end{tabular}

$n=$ Four to six rats in each group. Data are expressed as means \pm SEM.

sodium loading in protecting from gentamicin-induced renal cortical mitochondrial dysfunction.

On the other hand, sodium depletion potentiated gentamicininduced renal injury. After six doses, renal cortical mitochondrial respiratory functions from animals on sodium-deficient diets (group 8) were significantly more impaired compared with those from rats on standard diets (group 7). In contrast to the lack of effect of calcium supplementation during sodium loading, calcium supplementation during sodium deprivation (group 9) resulted in protecting against almost all mitochondrial respiratory declines induced by gentamicin.

Renal cortical homogenate and mitochondrial calcium content. Table VI summarizes calcium content data from groups 3-9. Sodium loading with $\mathrm{NaCl}$ (group 4) prevented the large increases in homogenate and mitochondrial calcium content observed in animals on standard diets (group 3) after eight doses of gentamicin. Calcium supplementation (group 5) or sodium supplementation with $\mathrm{NaHCO}_{3}$ (group 6) did not add further to the protection from cellular and mitochondrial calcium overload afforded by $\mathrm{NaCl}$ supplementation (group 4), since renal cortical homogenate and mitochondrial calcium content values from groups 5 and 6 were not significantly different from group 4 values.

After six doses of gentamicin, sodium depletion (group 8) significantly increased homogenate and mitochondrial calcium content values compared with those from rats on standard diets (group 7). Calcium supplementation during sodium deprivation (group 9) prevented the potentiation of cellular and mitochondrial calcium overload produced by sodium depletion. Values from group 9 were significantly lower than those from group 8 .

\section{Discussion}

The divalent cations, $\mathrm{Ca}^{++}$and $\mathrm{Mg}^{++}$, have been clearly shown to alter a variety of aminoglycoside-membrane events. The aminoglycosides inhibit calcium binding to artificial phospholipid membranes (14). Calcium and magnesium diminish aminoglycoside binding and transport by bacterial membranes (15). Aminoglycosides alter inner mitochondrial membrane function in vitro primarily by displacing $\mathrm{Mg}^{++}$from sites along the inner mitochondrial membrane that control monovalent cation permeability, and $\mathrm{Mg}^{++}$can reverse these effects $(21,22)$. Gentamicin also inhibits mitochondrial $\mathrm{Ca}^{++}$uptake (23). Gentamicin interferes with the slow calcium channels of the sarcolemma in the atrial myocardium of guinea pigs (16). Gentamicin inhibits the glucose transporter of isolated BBM vesicles in vitro and this inhibition is prevented by magnesium (19). Likewise, the inhibition of the antidiuretic hormone-responsive adenylate cyclase of the toad urinary bladder by gentamicin is prevented by $\mathrm{Mg}^{++}(20)$. Thus, there is ample evidence that divalent cations modify aminoglycoside-membrane interactions and may prevent many aminoglycoside-induced membrane alterations and aminoglycoside-induced toxicities. In this regard, aminoglycosideinduced neuromuscular blockade is due to displacement of membrane-bound calcium, resulting in an inhibition of the prejunctional release of acetylcholine (17) and a decrease in the sensitivity of the motor end plate to the depolarizing action of acetylcholine (18). This blockade is reversed by $\mathrm{Ca}^{++}(18)$. Calcium also acutely prevents gentamicin-induced loss of cochlear microphonics in vitro (33). These reports demonstrate the ability of divalent cations to prevent and reverse aminoglycoside-induced neurotoxicity and ototoxicity acutely in vitro. In a similar fashion, recent reports $(1,34)$ have demonstrated that oral calcium loading protects against gentamicin-induced acute renal excretory failure. The present experiments were undertaken to better characterize the effect of dietary calcium supplementation to ameliorate aminoglycoside-induced nephrotoxicity. To increase $\mathrm{Ca}^{++}$delivery to the kidney, rats were placed on a standard rat chow diet supplemented with $4 \% \mathrm{Ca}^{++}$by weight in the form of $\mathrm{CaCO}_{3}$. This dietary manipulation has been demonstrated to increase urinary calcium excretion $>10$ - to 20 -fold $(34,35)$. Calcium supplementation in this manner dramatically ameliorated the gentamicin-induced decline in renal excretory function, as measured by elevations in BUN, observed in rats on standard diets. This finding confirms the protective effect of

Table IV. Effect of Gentamicin on BUN Levels in Rats on Various Dietary Regimens

\begin{tabular}{llc}
\hline Group & $\begin{array}{l}\text { Gentamicin } \\
\text { doses }\end{array}$ & BUN \\
\hline & & $m g / d l$ \\
Standard diet (group 3) & 8 & $120 \pm 20$ \\
$\mathrm{NaCl}$ supplemented (group 4) & 8 & $51 \pm 5^{*}$ \\
$\mathrm{NaCl}+\mathrm{CaCO}_{3}$ supplemented (group 5) & 8 & $51 \pm 5$ \\
$\mathrm{NaHCO}_{3}$ supplemented (group 6) & 8 & $55 \pm 14$ \\
Standard diet (group 7) & 6 & $36 \pm 6$ \\
$\mathrm{Na}$ deficient (group 8) & 6 & $107 \pm 8^{*}$ \\
$\mathrm{Na}$ deficient $+\mathrm{CaCO}_{3}$ (group 9) & 6 & $31 \pm 7^{*}$ \\
\hline
\end{tabular}

Data presented as means \pm SEM.

${ }^{*} P<0.001$ compared with preceding group. 
Table V. Effects of Gentamicin Treatment on Basic Respiratory Parameters of Renal Cortical Mitochondria Isolated from Rats on Various Diets

\begin{tabular}{|c|c|c|c|c|c|c|c|c|c|c|}
\hline \multirow[b]{2}{*}{ Group } & \multirow[b]{2}{*}{ Doses } & \multicolumn{4}{|c|}{ Pyruvate-malate } & \multicolumn{4}{|l|}{ Succinate } & \multirow{2}{*}{$\begin{array}{l}\text { TMPD- } \\
\text { ascorbate }\end{array}$} \\
\hline & & S3 & S4 & ACR & DNP & S3 & S4 & ACR & DNP & \\
\hline \multirow{2}{*}{$\begin{array}{l}\text { Standard diet (group 3) } \\
\quad(n=6)\end{array}$} & & 68 & 24 & 2.72 & 40 & 136 & 64 & 2.11 & 159 & 230 \\
\hline & 8 & \pm 10 & \pm 2 & \pm 0.26 & \pm 5 & \pm 14 & \pm 4 & \pm 0.16 & \pm 16 & \pm 23 \\
\hline \multirow{2}{*}{$\begin{array}{l}\mathrm{NaCl} \text { supplemented (group 4) } \\
\quad(n=14)\end{array}$} & 8 & 83 & 24 & $3.53^{*}$ & 50 & $162 \ddagger$ & 66 & $2.47 \S$ & 182 & 247 \\
\hline & & \pm 14 & \pm 5 & \pm 0.43 & \pm 11 & \pm 6 & \pm 9 & \pm 0.15 & \pm 26 & \pm 47 \\
\hline \multirow{2}{*}{$\begin{array}{l}\mathrm{NaCl}+\mathrm{CaCO}_{3} \text { supplemented } \\
\quad \text { (group 5) }(n=7)\end{array}$} & 8 & 85 & 24 & $3.62 \ddagger$ & 56 & 184 & 70 & $2.58 \ddagger$ & 193 & 275 \\
\hline & & \pm 8 & \pm 2 & \pm 0.23 & \pm 7 & \pm 23 & \pm 6 & \pm 0.12 & \pm 22 & \pm 27 \\
\hline \multirow{2}{*}{$\begin{array}{l}\mathrm{NaHCO}_{3} \text { supplemented } \\
\quad \text { (group 6) }(n=6)\end{array}$} & 8 & 102 & $32^{\|}$ & 3.14 & $65 \pi$ & $223^{\|}$ & $87^{\prime \prime}$ & 2.56 & $243^{\prime \prime}$ & $299^{* *}$ \\
\hline & & \pm 8 & \pm 2 & \pm 0.15 & \pm 5 & \pm 17 & \pm 4 & \pm 0.15 & \pm 16 & \pm 17 \\
\hline \multirow{2}{*}{$\begin{array}{l}\text { Standard diet (group 7) } \\
\quad(n=6)\end{array}$} & 6 & 83 & 26 & 3.12 & 47 & 176 & 73 & 2.40 & 197 & 246 \\
\hline & & \pm 7 & \pm 2 & \pm 0.08 & \pm 5 & \pm 15 & \pm 5 & \pm 0.12 & \pm 15 & \pm 29 \\
\hline \multirow[t]{2}{*}{ Na deficient (group 8) $(n=6)$} & 6 & $41 \ddagger \ddagger$ & 25 & 2.23 & $23 \ddagger \ddagger$ & $98 \ddagger \ddagger$ & $51 \S \S$ & $1.90^{11 \|}$ & $111 \ddagger \ddagger$ & 188 \\
\hline & & \pm 6 & \pm 4 & \pm 0.34 & \pm 3 & \pm 9 & \pm 8 & \pm 0.05 & \pm 11 & \pm 27 \\
\hline \multirow{2}{*}{$\begin{array}{l}\mathrm{Na} \text { deficient }+\mathrm{CaCO}_{3} \\
\text { supplemented (group 9) } \\
(n=6)\end{array}$} & 6 & 87ศा & 26 & 3.32 & 47Лा & 205ศा & $80 \pi \uparrow$ & $2.53 \pi \%$ & $235 \pi$ ग & $325 \pi \pi$ \\
\hline & & \pm 9 & \pm 2 & \pm 0.19 & \pm 7 & \pm 21 & \pm 4 & \pm 0.14 & \pm 24 & \pm 28 \\
\hline
\end{tabular}

Respiratory rates are given as mean nanoatom equivalents of oxygen per milligram protein per minute $\pm \mathrm{SEM}$. $n$ indicates number of animals in each group.

* $P<0.01$, group 4 or 5 vs. group 3 .

$\ddagger P<0.05$, group 4 or 5 vs. group 3 .

$\S P<0.02$, group 4 or 5 vs. group 3 .

" $P<0.001$, group 6 vs. group 4 .

I $P<0.02$, group 6 vs. group 4 .

** $P<0.05$, group 6 vs. group 4 .

$\ddagger \ddagger P<0.01$ group 8 vs. group 7 .

$\S \S P<0.02$ group 8 vs. group 7 .

"I" $P<0.05$ group 8 vs. group 7 .

กा $P<0.01$ group 9 vs. group 8 .

oral calcium loading on gentamicin-induced renal excretory failure recently reported by Bennett and co-workers $(1,34)$.

Calcium supplementation may ameliorate gentamicin-induced declines in renal excretory function and increases in BUN by either alleviating functional hemodynamic alterations at the glomerular level (36) or preventing structural cellular damage at the tubular level. If calcium was preventing the activity of gentamicin interactions with renal membranes to mediate membrane dysfunction, tubular cell injury, and, eventually, renal excretory failure, then the degree of renal tubular cell injury should be less in the calcium-supplemented group. In approaching this issue, however, broader questions arise, primarily because in attempting to understand the pathogenesis of the decline in renal excretory function in both nephrotoxic and ischemic acute renal failure, much of the work over the past two decades has focused on the nephronal determinants of renal excretory failure during acute renal failure. These determinants

have been intratubular obstruction, backleak of glomerular filtrate through damaged tubular epithelium, and primary alterations in the hemodynamic factors controlling glomerular filtration. Although understanding the nephronal mechanisms for acute renal failure has been extremely elucidative, it is clear that the final common pathogenetic pathway for the development of either ischemic or nephrotoxic acute renal failure is renal tubular cell injury (6-8). Without renal cell injury, the various factors responsible at the nephronal level for excretory failure of the kidney would not be initiated. Ultimately, the understanding of the pathogenesis of acute tubular necrosis resides in the understanding of the critical biochemical alterations responsible for the loss of renal cell integrity, but only recently have these biochemical events become areas of increased investigation, so that the manner in which to best quantitatively assess the magnitude of renal tubular cell injury in developing injury has not been well defined. Morphologic studies have been useful but they are prone to sampling errors, fixation artifacts, and grading difficulties. Additionally, substantial functional changes may occur before necrosis. Increasing evidence suggests that nephrotoxins and ischemia exert their primary detrimental effects on cells by disturbing the membrane phase of the cell (6-8). Both the plasma membrane and the intracellular organellar membranes are potential sites of toxicity. Of the subcellular membranes, because of the high metabolic demands of epithelial transport, the mitochondrial membrane assumes primary importance in the renal tubular cell. Recent studies from our lab- 
Table VI. Calcium Contents of Renal Cortical Homogenates and Mitochondria from Rats Treated with Gentamicin and Ingesting Various Diets

\begin{tabular}{lll}
\hline Group & Homogenate calcium content & Mitochondrial calcium content \\
\hline & $n$ mol/mg protein & $n$ mol/mg protein \\
Standard diet (group 3) & $80.2 \pm 40.3$ & $61.8 \pm 19.0$ \\
$\mathrm{NaCl}$ supplemented (group 4) & $27.6 \pm 2.0^{*}$ & $38.8 \pm 9.6^{*}$ \\
$\mathrm{NaCl}+\mathrm{CaCO}_{3}$ supplemented & & $36.3 \pm 6.3$ \\
$\quad$ (group 5) & $24.8 \pm 6.4$ & $34.9 \pm 5.2$ \\
$\mathrm{NaHCO}$ supplemented & & $22.9 \pm 2.5$ \\
$\quad$ group 6) & $26.8 \pm 4.2$ & $54.8 \pm 9.7 \ddagger$ \\
$\mathrm{Standard} \mathrm{diet} \mathrm{(group} \mathrm{7)}$ & $21.0 \pm 4.4$ & \\
$\mathrm{Na}$ deficient (group 8) & $71.0 \pm 11.2 \ddagger$ & $33.7 \pm 10.6 \S$ \\
$\mathrm{Na}$ deficient $+\mathrm{CaCO}_{3}$ & & \\
supplemented (group 9) & $24.7 \pm 6.0 \S$ & \\
\hline
\end{tabular}

Data expressed as means \pm SEM.
${ }^{*} P<0.05$ group 4 vs. group 3.
$\ddagger P<0.01$ group 8 vs. group 7.
$\S P<0.02$ group 9 vs. group 8.

oratory have demonstrated that renal cortical mitochondrial function and renal cortical homogenate calcium content, as a reflection of altered plasma membrane permeability to $\mathrm{Ca}^{++}$, can be valuable quantitative measurements of renal tubular injury in developing nephrotoxic acute renal failure (2-8).

Since dying cells lose their ability to control intracellular calcium within normally low levels, injured cells develop progressive degrees of calcium overload, and the calcium content found in renal cortical homogenates can help quantitate the extent of advanced renal tubular cell injury present $(2-5)$. The data in this study by demonstrating a strong correlation between the declines in renal excretory function, as measured by BUN, and the degree of renal proximal tubular cell injury, as measured by renal cortical homogenate calcium content, support this thesis. Values for BUN and homogenate calcium content from group 1 and 2 rats after 10 doses of gentamicin correlated well with an $r$ value of 0.86 . Furthermore, a clear segregation of values between groups 1 and 2 occurred. Rats on calcium supplementation (group 2) had BUN values never $>50 \mathrm{mg} / \mathrm{dl}$, while every rat on a standard diet (group 1) had BUN values $>50$ $\mathrm{mg} / \mathrm{dl}$. Likewise, all rats receiving calcium supplementation had renal cortical homogenate calcium contents $<25 \mathrm{nmol} / \mathrm{mg}$ protein, while all rats on standard diets had values $\geq 25 \mathrm{nmol} / \mathrm{mg}$ protein. Thus, calcium supplementation appears to be affecting primary pathogenetic pathways to ameliorate gentamicin-induced renal tubular cell injury.

Renal cortical mitochondrial function is also significantly altered in developing nephrotoxic acute renal failure $(3,26,37$, 38 ) and has been used, along with renal cortex homogenate calcium content, as a quantitative guide to the extent of renal cell damage in developing acute renal failure (2-8). After four doses, mitochondrial function from rats on both standard and calcium-supplemented diets (groups 1 and 2) was altered. These derangements reflect early alterations preceding loss of renal tubular cell integrity, as assessed morphologically, and precede organ failure, as measured by a rise in BUN, and occur before mitochondrial and cellular calcium overload. The time course for these changes in gentamicin nephrotoxicity has been detailed previously $(3,37)$. Renal cortical mitochondrial respiratory parameters from both groups progressively worsened with increasing dosage, so that after six doses all respiratory parameters were significantly lower in group 1 compared with control values. Respiration supported by pyruvate-malate, succinate and TMPD-ascorbate were all substantially affected, demonstrating major derangements along all segments of the electron transport chain of the inner mitochondrial membrane (8). This further progressive deterioration in mitochondrial function is related to the occurrence of mitochondrial calcium overload, which develops as the extent and degree of cell injury progresses (3). Using mitochondrial dysfunction as a parameter of renal tubular cell injury, after eight doses, significant differences in most respiratory parameters between groups 1 and 2 were observed. After 10 doses, all respiratory parameters were significantly better in mitochondria isolated from rats on calcium-supplemented diets than in organelles isolated from animals on standard diets. Calcium supplementation clearly preserved renal cortical mitochondrial function in the later stages of gentamicin nephrotoxicity.

The mechanism by which calcium loading ameliorates gentamicin nephrotoxicity is presently unclear. Since gentamicininduced plasma and subcellular membrane injury appear to be critical pathogenetic events in gentamicin nephrotoxicity (6-8), $\mathrm{Ca}^{++}$may be competitively inhibiting critical gentamicin-renal membrane interactions that lead to cell injury. In this regard, multiple binding sites for the aminoglycoside antibiotics have been characterized in a variety of membranes (9-13). For developing toxicity, the high affinity site is most critical and has been recently identified as the acidic phospholipids of the membrane $(9,10)$. This binding reaction is due to a charge interaction between these polycationic antibiotics and the anionic head 
groups of acidic phospholipids. Not surprisingly, as discussed above, a number of studies have demonstrated that the divalent cations, calcium and magnesium, interfere with a large variety of membrane-aminoglycoside interactions. The experiments of the present studies have demonstrated that $\mathrm{Ca}^{++}$is a competitive inhibitor of ${ }^{125}$ I-gentamicin binding to isolated renal BBMs, the initial membrane site of interaction between gentamicin and renal proximal tubule cells (39). $\mathrm{Ca}^{++}$with a $K_{\mathrm{i}}$ of $12 \mathrm{mM}$ was more effective than $\mathrm{Mg}^{++}$, which had a $K_{\mathrm{i}}$ of $21 \mathrm{mM}$. Of note, more than one binding site exists for aminoglycosides in a variety of membranes (9-13); both high affinity sites with a dissociation constant $\left(K_{\mathrm{d}}\right)$ of $20-30 \mu \mathrm{M}$ and low affinity sites with $K_{\mathrm{d}} \mathrm{s}$ of $\sim 300 \mu \mathrm{M}$ and $1 \mathrm{mM}$ exist. The $K_{\mathrm{i}}$ of $12 \mathrm{mM}$ for $\mathrm{Ca}^{++}$in BBMs is high and reflects a composite $K_{\mathrm{i}}$ for $\mathrm{Ca}^{++}$-gentamicin competition at both high and low affinity binding sites. The $K_{\mathrm{i}}$ derived for BBMs by the Dixon plot in this study is determined predominantly by the values obtained at high millimolar $\mathrm{Ca}^{++}$ concentrations, concentrations that are most likely displacing the component of gentamicin binding to low affinity sites. With regard to toxicity, the high affinity sites that are composed of the acidic phospholipids of the membrane are likely to be the most critical, since their $K_{\mathrm{d}} \mathrm{s}$ correspond more closely to serum levels of gentamicin associated with clinical and experimental toxicity (9). Since acidic phospholipids are the high affinity membrane binding sites for aminoglycosides, the $K_{\mathrm{i}}$ of $170 \mu \mathrm{M}$ for $\mathrm{Ca}^{++}$to competitively inhibit gentamicin binding to phosphatidic acid probably reflects the most critical $\mathrm{Ca}^{++}$-gentamicinmembrane interaction. It would certainly be desirable to quantitatively prove that the $K_{\mathrm{i}}$ for $\mathrm{Ca}^{++}$at the high affinity site is near $170 \mu \mathrm{M}$, as suggested by the interaction between gentamicin, $\mathrm{Ca}^{++}$, and pure phosphatidic acid. But because of the existence of multiple gentamicin binding sites and of at least two $\mathrm{Ca}^{++}$ binding sites in BBMs (40) and because $\mathrm{Ca}^{++}$competes with gentamicin at all these sites, the $K_{\mathrm{i}}$ for $\mathrm{Ca}^{++}$at this high affinity site within BBMs cannot be quantitated with precision. In fact, it should be emphasized that the exact $K_{\mathrm{i}}$ for $\mathrm{Ca}^{++}$to compete with gentamicin at the high affinity aminoglycoside binding site of BBMs cannot be determined with present techniques. The $K_{\mathrm{i}}$ of $12 \mathrm{mM}$ is a composite $K_{\mathrm{i}}$ for $\mathrm{Ca}^{++}$competing at both high and low affinity binding sites within BBMs. There is ample reason, however, to believe that the $K_{\mathrm{i}}$ for $\mathrm{Ca}^{++}$to compete for gentamicin binding to acidic phospholipids in biological membranes is in the micromolar range: Gentamicin binds to acidic phospholipids in biological membranes with a $K_{\mathrm{d}}$ of $25 \mu \mathrm{M}$ (9); $\mathrm{Ca}^{++}$binds to acidic phospholipids in biological membranes with a $K_{\mathrm{d}}$ of $25 \mu \mathrm{M}(41)$; and aminoglycosides displace $\mathrm{Ca}^{++}$ from the acidic phospholipids of lipid monolayers with $K_{\mathrm{i}} \mathrm{s}$ of 1-6 $\mu \mathrm{M}$ (42). Thus, all the relevant interactions between gentamicin and $\mathrm{Ca}^{++}$with acidic phospholipids in biological membranes occur in the micromolar range. Since the concentration of $\mathrm{Ca}^{++}$within the lumen of the renal proximal tubule is in the millimolar range, small increases in the luminal concentration of $\mathrm{Ca}^{++}$may significantly diminish gentamicin binding to the critical high affinity binding site of the BBM, resulting in amelioration of toxicity. If this $\mathrm{Ca}^{++}$effect was mediated primarily by events along the luminal membrane, since binding of gen- tamicin to BBMs is a critical step in the uptake of the antibiotic by the kidney, interference by $\mathrm{Ca}^{++}$at this site should result in lower renal cortical accumulation of gentamicin. No differences in the time course or peak gentamicin levels were demonstrated between animals on calcium supplemented and animals on standard diets, arguing against this possibility. However, it is well established that a large portion of gentamicin is inactive and sequestered in phagolysosomes within the proximal tubule cell (6), differences in a small but actively toxic pool of gentamicin may exist but may be difficult to demonstrate quantitatively.

Another possibility may be that $\mathrm{Ca}^{++}$prevents critical cellular derangements induced by gentamicin within the renal tubular cell rather than on its cell surface. Since gentamicin has been demonstrated to induce alterations in the structure and function of a variety of subcellular membranes produced by the antibiotic $(21,22,24)$, prevention by calcium of subcellular membrane dysfunction may be an additional mechanism for its protective effect. That $\mathrm{Ca}^{++}$may be having a major subcellular effect to prevent gentamicin-induced renal cell injury is suggested by the influence dietary sodium manipulations had on the protective effect of oral calcium loading. Since sodium and calcium transport are directly linked to one another along the proximal tubule, volume expansion leads to inhibition of $\mathrm{Ca}^{++}$transport and sodium depletion leads to elevations in $\mathrm{Ca}^{++}$transport along the proximal tubule (31). In this regard, sodium supplementation with $\mathrm{NaCl}$ ameliorated gentamicin toxicity, as measured by elevations in BUN, declines in mitochondrial respiratory parameters, and increases in homogenate and mitochondrial calcium content. In the presence of volume expansion with $\mathrm{NaCl}$ loading, however, calcium supplementation did not further ameliorate gentamicin-induced renal excretory failure and renal cell injury than that seen with $\mathrm{NaCl}$ loading alone. In fact, all absolute respiratory rates from mitochondria isolated from volume-expanded rats receiving $\mathrm{Ca}^{++}$supplementation (group 5) were more affected than those from non-volume-expanded animals receiving standard $\mathrm{Ca}^{++}$supplemented diets (group 2) after eight doses of gentamicin; furthermore, higher homogenate and mitochondrial calcium contents were found in group 5 than in group 2 after either eight or 10 doses. Thus, calcium loading in the presence of volume expansion, which would diminish reabsorptive rates for calcium along the proximal tubule, was not as protective against renal cell injury as calcium loading in the standard diet state. However, because the degree of renal tubular cell injury and renal excretory failure produced by gentamicin during sodium supplementation was not severe, an additional protective effect of oral calcium loading in this group may not be apparent.

Sodium depletion, on the other hand, potentiated gentamicin nephrotoxicity. The degree of renal injury that developed after 10 doses in rats on standard diets (group 1) was similar to that occurring after only six doses in animals on sodium-deficient diets (group 8 ). This potentiation has been reported previously (30). Calcium supplementation in this setting provided significant protection against gentamicin-induced renal excretory failure, as measured by BUN, and renal cell injury, as measured by mitochondrial function and homogenate and mitochondrial 
calcium content. Calcium loading in the setting of sodium depletion, a state in which $\mathrm{Ca}^{++}$reabsorption is increased along the proximal tubule, retained its protective effect against gentamicin nephrotoxicity.

Finally, calcium supplementation was accomplished in these studies by the addition of $\mathrm{CaCO}_{3}$ to the diet. Not only is the cation, $\mathrm{Ca}^{++}$, ingested but also its accompanying alkaline anion, $\mathrm{CO}_{3}^{-2}$. Alkalinization with $\mathrm{HCO}_{3}^{-}$loading has been associated both with improvement and no improvement of gentamicininduced acute renal failure in previous reports $(32,43)$. In this study, $\mathrm{NaHCO}_{3}$ supplementation was no better than an equimolar supplementation with $\mathrm{NaCl}$ in protecting against a rise in BUN or homogenate and mitochondrial calcium content but was slightly better in protecting against mitochondrial injury. No major protective role for $\mathrm{HCO}_{3}^{-}$alone on gentamicin nephrotoxicity could thus be demonstrated in this study, suggesting that the protective effect of $\mathrm{CaCO}_{3}$ supplementation on gentamicin nephrotoxicity appears to reside primarily in $\mathrm{Ca}^{++}$.

The protective role of $\mathrm{Ca}^{++}$in this form of toxin-induced cell injury contrasts to the detrimental effects of mitochondrial and cellular $\mathrm{Ca}^{++}$overload on cell viability in most forms of ischemic and toxic cell injury $(7,8,44)$. In this regard and of considerable importance are the recent preliminary findings that demonstrated that major elevations in serum $\mathrm{Ca}^{++}$levels and renal tubular flux of $\mathrm{Ca}^{++}$potentiate gentamicin-induced acute renal failure by increasing the rate of development of tissue and mitochondrial $\mathrm{Ca}^{++}$overload (45). In view of this data, it appears that the protective role of dietary calcium supplementation in aminoglycoside-induced toxic cell injury resides in the unique competitive role of this divalent cation to inhibit toxin-membrane interactions and its ability to only modestly increase serum levels and proximal tubular flux of $\mathrm{Ca}^{++}$.

Dietary calcium supplementation may ameliorate gentamicin-induced renal damage by additional mechanisms. This dietary manipulation may increase luminal urine flow secondary to a solute diuresis resulting in a lower intraluminal gentamicin concentration, a decrease in renal cortex concentration of the antibiotic, and a lesser toxic effect, such as occurs with the protection afforded by the natriuresis during a high sodium diet. In this regard, recent reports have demonstrated that adult rats placed on a $4 \%$ calcium-supplemented diet do not develop a solute or sodium diuresis $(1,34,35)$, so that it is unlikely that the protective effect of this diet is mediated by the development of a solute diuresis. A decline in circulating parathyroid hormone (PTH) levels may also participate in the effect. PTH has been shown to increase the levels of acidic phospholipids in the renal cortex $(46,47)$. Suppression of PTH release by oral calcium loading may result in a decline in the number of high affinity binding sites in the renal tubular cell, diminish gentamicinmembrane interactions, and reduce the toxic potential of the antibiotic. Recent data suggest that this possibility is also unlikely (48). A final possible factor that may contribute to this protective effect may be related to the phosphate ion. A recent study has shown that dietary calcium supplementation produces phosphate depletion and declines in serum phosphate (49). Since cellular calcium overload, occurring in part as calcium phosphate, is an important determinant of the time course and degree of cell injury (44), declines in serum and cellular phosphate may lessen the amount of cellular calcium overload and, thus, the degree of cell injury produced by a toxic or ischemic event. Certainly, phosphate loading has been shown to potentiate acute renal failure (50). Future studies will undoubtedly shed further insight into these possibilities.

In summary, these experiments have: $(a)$ confirmed that dietary calcium loading protects against gentamicin-induced acute renal failure, $(b)$ determined that this protection is based upon amelioration of the degree of gentamicin-induced renal tubule cell injury as assessed by several critical biochemical parameters, and $(c)$ suggested that this protective effect is consistent with an ability of $\mathrm{Ca}^{++}$to act as a competitive inhibitor of gentamicin-renal membrane interactions primarily at subcellular rather than cell surface sites of the renal proximal tubule cell.

\section{Acknowledgments}

The excellent technical assistance of Phillip Harding and Mary Clark is appreciated.

These studies were supported, in part, by the Veterans Administration Research Service, by Public Health Service grant 1-R01-AM30879-01, and by a grant from the National Kidney Foundation of Michigan.

\section{References}

1. Bennett, W. M., C. W. Elliott, D. C. Houghton, D. N. Gilbert, J. DeFehr, and D. A. McCarron. 1982. Reduction of experimental gentamicin nephrotoxicity in rats by dietary calcium loading. Antimicrob. Agents Chemother. 22:508-512.

2. Weinberg, J. M., and H. D. Humes. Renal tubular integrity during mercuric chloride and gentamicin nephrotoxicity. In Acute Renal Failure: Correlations between Morphology and Function. K. Solez and W. Whelton, editors. Marcel Dekker, Inc., New York. In press.

3. Weinberg, J. M., P. G. Harding, and H. D. Humes. 1983. Alterations in renal cortex cation homeostasis during mercuric chloride and gentamicin nephrotoxicity. Mol. Exp. Path. 39:43-60.

4. Weinberg, J. M., P. G. Harding, and H. D. Humes. 1982. Saline loading protects against tubular injury in $\mathrm{HgCl}_{2}$ nephrotoxicity. Kidney Int. 21:226. (Abstr.)

5. Sastrasinh, M., J. M. Weinberg, and H. D. Humes. 1983. The degree of gentamicin-induced acute renal failure in various states of sodium balance is due to structural rather than functional renal abnormalities. Kidney Int. 23:207. (Abstr.)

6. Humes, H. D., J. M. Weinberg, and T. C. Knauss. 1982. Clinical and pathophysiologic aspects of aminoglycoside nephrotoxicity. Am. J. Kid. Dis. 2:5-29.

7. Humes, H. D., and J. M. Weinberg. 1983. Alterations in renal tubular cell metabolism in acute renal failure. Miner. Electrolyte Metab. 9:290-305.

8. Humes, H. D., and J. M. Weinberg. 1983. Cellular energetics in acute renal failure. In Acute Renal Failure. B. M. Brenner and J. M. Lazarus, editors. W. B. Saunders Co., Philadelphia. 47-98.

9. Sastrasinh, M., T. C. Knauss, J. M. Weinberg, and H. D. Humes. 1982. Identification of the aminoglycoside binding site of renal brush border membranes. J. Pharmacol. Exp. Ther. 222:350-359.

10. Schacht, J. 1979. Isolation of an aminoglycoside receptor from guinea pig inner ear tissues and kidney. Arch. Oto-Rhino-Laryngol. 224:129-134.

11. Just, M., and E. Habermann. 1977. The renal handling of poly- 
basic drugs. II. In vitro studies with brush border and lysosomal preparations. Naunyn-Schmiedeberg's Arch. Pharmacol. 300:67-76.

12. Lipsky, J. J., L. Cheng, B. Sacktor, and P. S. Lietman. 1980. Gentamicin uptake by renal tubule brush border membrane vesicles. J. Pharmacol. Exp. Ther. 215:390-393.

13. Anniko, M., D. Bagger-Sjöbäck, J. Wersăll, and J. Schacht. 1982. Gentamicin binding to the isolated crista ampullaris of the guinea pig. Res. Commun. Chem. Pathol. Pharmacol. 37:333-342.

14. Lodhi, S., N. D. Weiner, and J. Schacht. 1976. Interactions of neomycin and calcium in synaptosomal membranes and polyphosphoinositide monolayers. Biochim. Biophys. Acta. 426:781-785.

15. Hancock, R. E. W. 1981. Aminoglycoside uptake and mode of action-with special reference to streptomycin and gentamicin. I. Antagonists and mutants. J. Antimicrob. Chemother. 8:249-276.

16. Adams, H. R., and L. R. Durrett. 1978. Gentamicin blockade of slow $\mathrm{Ca}^{++}$channels in atrial myocardium of guinea pigs. J. Clin. Invest. 62:241-247.

17. Vital-Brazil, O., and J. Prado-Franceschi. 1969. The nature of the neuromuscular block produced by neomycin and gentamicin. Arch. Int. Pharmacodyn. Ther. 179:78-85.

18. Pittinger, C., and R. Adamson. 1972. Antibiotic blockage of neuromuscular function. Ann. Rev. Pharmacol. 12:169-184.

19. Sastrasinh, M., J. M. Weinberg, and H. D. Humes. 1982. Effect of gentamicin on glucose transport by isolated renal brush border membranes. Clin. Res. 30:462A. (Abstr.)

20. Humes, H. D., and J. M. Weinberg. 1983. Effect of gentamicin on $\mathrm{ADH}$-induced hydroosmotic water flow in the toad urinary bladder. J. Lab. Clin. Med. 101:472-478.

21. Weinberg, J. M., and H. D. Humes. 1980. Mechanisms of gentamicin-induced dysfunction of renal cortical mitochondria. I. Effects on mitochondrial respiration. Arch. Biochem. Biophys. 205:222-231.

22. Weinberg, J. M., P. G. Harding, and H. D. Humes. 1980. Mechanisms of gentamicin-induced dysfunction of renal cortical mitochondria. II. Effects of mitochondrial monovalent cation transport. Arch. Biochem. Biophys. 205:232-239.

23. Sastrasinh, M., J. M. Weinberg, and H. D. Humes. 1982. Effect of gentamicin on calcium uptake by renal mitochondria. Life Sci. 30:2309-2315.

24. Knauss, T. C., J. M. Weinberg, and H. D. Humes. 1983. Alterations in renal cortical phospholipid content induced by gentamicin time course, specificity and subcellular localization. Am. J. Physiol. 244:F535-F546.

25. Weinberg, J. M., P. G. Harding, and H. D. Humes. 1982. Mitochondrial bioenergetics during the initiation of mercuric chloride renal injury. I. Direct effects of in vitro mercuric chloride on renal cortical mitochondrial function. J. Biol. Chem. 257:60-67.

26. Weinberg, J. M., P. G. Harding, and H. D. Humes. 1982. Mitochondrial bioenergetics during the initiation of mercuric chloride renal injury. II. Functional alterations of renal cortical mitochondria isolated after mercuric chloride treatment. J. Biol. Chem. 257:68-74.

27. Lowry, O. H., N. J. Rosebrough, A. L. Farr, and R. J. Randall. 1951. Protein measurement with the Folin phenol reagent. J. Biol. Chem. 193:265-275.

28. Nicholls, D. G., and M. Crompton. 1980. Mitochondrial calcium transport. FEBS (Fed. Eur. Biochem. Soc.) Lett. 111:261-268.

29. Clark, M., J. M. Weinberg, and H. D. Humes. 1983. Mitochondrial calcium transport by normal renal cortical mitochondria during their isolation. Kidney Int. 23:202. (Abstr.)

30. Bennett, W. M., M. N. Hartnett, D. Gilbert, D. Houghton, and G. A. Porter. 1976. Effect of sodium intake on gentamicin nephrotoxicity in the rat. Proc. Soc. Exp. Biol. Med. 151:736-738.

31. Goldberg, M., Z. S. Agus, and S. Goldfarb. 1976. Renal handling of phosphate, calcium, and magnesium. In The Kidney. B. M. Brenner and F. C. Rector, editors. W. B. Saunders Co., Philadelphia. 344-390.

32. Chiu, P. J. S., G. H. Miller, J. F. Long, and J. A. Waitz. 1979. Renal uptake and nephrotoxicity of gentamicin during urinary alkalinization in rats. Clin. Exp. Pharmacol. Physiol. 6:317-326.

33. Takada, A., and J. Schacht. 1982. Calcium antagonism and reversibility of gentamicin-induced loss of cochlear microphonics in the guinea pig. Hear. Res. 8:179-186.

34. Quarum, M., D. C. Houghton, D. N. Gilbert, D. A. McCarron, and W. M. Bennett. 1983. High calcium intake modifies experimental gentamicin nephrotoxicity. Clin. Res. 31:76A. (Abstr.)

35. McCarron, D. A. 1982. Calcium, magnesium, and phosphorus balance in human and experimental hypertension. Hypertension (Dallas). 4(Suppl. III):III-27-III-33.

36. Schor, N., I. Ichikawa, H. G. Rennke, J. L. Troy, and B. M. Brenner. 1981. Pathophysiology of altered glomerular function in aminoglycoside-treated rats. Kidney Int. 19:288-296.

37. Simmons, C. F., Jr., R. T. Bogusky, and H. D. Humes. 1980. Inhibitory effects of gentamicin on renal mitochondrial oxidative phosphorylation. J. Pharmacol. Exp. Ther. 214:709-715.

38. Simmons, C. F., Jr., H. Rennke, and H. D. Humes. 1981. Diethylaminoethyl dextran nephrotoxicity: importance of cationic charge. Kidney Int. 19:424-430.

39. Just, M., G. Erdman, and E. Haberman. 1977. The renal handling of polybasic drugs. I. Gentamicin and aprotinin in intact animals. Naunyn-Schmiedeberg's Arch. Pharmacol. 300:57-66.

40. Somermeyer, M. G., T. C. Knauss, J. M. Weinberg, and H. D. Humes. 1983. Characterization of calcium transport in renal brush border membranes and its modulation by phosphatidic acid. Biochem. J. 214: $37-46$.

41. Buckley, J. T., and J. N. Hawthorne. 1972. Erythrocyte membrane polyphosphoinositide metabolism and the regulation of calcium binding. J. Biol. Chem. 247:7218-7223.

42. Lüllmann, H., and B. Vollmer. 1982. An interaction of aminoglycoside antibiotics with $\mathrm{Ca}$ binding to lipid monolayers and to biomembranes. Biochem. Pharmacol. 31:3769-3773.

43. Elliott, W. C., R. A. Parker, D. C. Houghton, D. N. Gilbert, G. A. Porter, J. DeFehr, and W. M. Bennett. 1980. Effect of sodium bicarbonate and ammonium chloride ingestion in experimental gentamicin nephrotoxicity in rats. Res. Commun. Chem. Pathol. Pharmacol. 28:483-495.

44. Farber, J. L. 1981. The role of calcium in cell death. Life Sci. 29:1289-1296.

45. Humes, H. D., M. Sastrasinh, and J. M. Weinberg. 1983. Modification of gentamicin-induced renal tubular cell injury and renal excretory failure. Clin. Res. 31:430A. (Abstr.)

46. Farese, R. V., P. Bidot-López, A. Sabir, J. S. Smith, B. Schinbeckler, and R. Larson. 1980. Parathyroid hormone acutely increases polyphosphoinositides of the rabbit kidney cortex by a cyclohexamidesensitive process. J. Clin. Invest. 65:1523-1526.

47. Meltzer, V., S. Weinreb, E. Bellorin-Font, and K. A. Hruska. 1982. Parathyroid hormone stimulation of renal phosphoinositide metabolism is a cyclic nucleotide-independent effect. Biochim. Biophys. Acta. 712:258-267.

48. Cronin, R. 1983. Role of PTH and thyroxine in gentamicininduced acute renal failure. Clin. Res. 31:549A. (Abstr.)

49. Chen, S., B. Eby, and K. Lau. 1983. Mechanism for the salutory effects of high diet calcium on blood pressure in spontaneous hypertensive rats. Kidney Int. 23:167. (Abstr.)

50. Zager, R. A., G. A. Johannes, and H. M. Sharma. 1982. Hyperphosphatemia: a factor that provokes severe experimental acute renal failure. J. Lab. Clin. Med. 100:230-237. 